\title{
Persistent hypermetabolism and longitudinal energy expenditure in critically ill patients with COVID-19
}

\author{
John Whittle ${ }^{1}$, Jeroen Molinger ${ }^{1}$, David MacLeod ${ }^{1}$, Krista Haines ${ }^{2}$, Paul E. Wischmeyer ${ }^{1,2^{*}}$ (D) for the LEEP-COVID \\ Study Group
}

Keywords: Metabolism, Nutrition, Indirect Calorimetry, SARS-CoV-2, ICU, Metabolic cart, VO2, VCO2

COVID-19 infection results in respiratory failure requiring ICU care in a small, yet significant, number of patients [1]. The longitudinal metabolic phenotype and energy expenditure of this novel pandemic disease has yet to be described. As a marked and often prolonged, systemic inflammatory response (SIRS) has been suggested to be a hallmark of severe COVID-19 infection [1], we hypothesized a prolonged hypermetabolic state would evolve over ICU stay that would persist beyond the 7-10 day hypermetabolic phase described previously in other ICU conditions [2].

Further, understanding the energy expenditure of COVID-19 ICU patients is essential to help determine safe, optimal nutrition needs for the ICU provider [3], as both over-/underfeeding is associated with increased ICU mortality [3, 4]. Prediction of resting energy expenditure (pREE) using standardized formulas or bodyweight calculations often correlates poorly with measured REE (mREE) [3]. Thus, our aim was to assess longitudinal mREE via indirect calorimetry (IC) in intubated COVID-19 patients.

Here, we report the first results from the LEEPCOVID study (clinicaltrials.gov NCT04350073) from
March to May, 2020. Following IRB approval, IC was conducted every $72 \mathrm{~h}$ (Q-NRG, COSMED/BAXTER, USA) [5]. Prior to testing, patients were confirmed to be in stable condition with only steady-state measures for $\geq 20$ min considered valid. mREE was compared to pREE, which was calculated at same timepoints via commonly utilized Harris-Benedict equation (HBE). For calculations, actual body weight (ABW) was used for non-obese $(\mathrm{BMI}<30)$ and both actual and adjusted body weight (AdjBW) was utilized for obese subjects (BMI > 30) [3].

Data from 22 COVID-19 ICU patients are summarized in Table 1 and Fig. 1. During the 1st ICU week, mREE was observed to fall between 15 and 20 $\mathrm{kcal} / \mathrm{kg}$ (for $\mathrm{ABW}$ in $\mathrm{BMI}<30$ and $\mathrm{AdjBW}$ in obese subjects [3].). Increasing hypermetabolism and wider variability in mREE were observed post-1st ICU week. Unlike data from smaller studies in other ICU populations [1], observed hypermetabolism persisted, and in fact increased during 3rd ICU week (mean $\mathrm{mREE}=150 \%$ pREE in 3rd ICU week). Certain individuals exhibited metabolic rates greater than two-times predicted via HBE, which significantly underpredicted REE post-1st ICU week. Changes in

\footnotetext{
* Correspondence: Paul.Wischemyer@duke.edu; Paul.Wischmeyer@Duke.edu 'Division of Critical Care, Human Pharmacology and Physiology Laboratory (HPPL), Department of Anesthesiology, Duke University School of Medicine, DUMC, Box 3094 Mail \# 41, 2301 Erwin Road, 5692 HAFS, Durham, NC 27710, USA

${ }^{2}$ Division of Trauma Critical Care, and Acute Care Surgery, Department of Surgery, Duke University School of Medicine, Durham, NC, USA
} changes were made. The images or other third party material in this article are included in the article's Creative Commons licence, unless indicated otherwise in a credit line to the material. If material is not included in the article's Creative Commons licence and your intended use is not permitted by statutory regulation or exceeds the permitted use, you will need to obtain permission directly from the copyright holder. To view a copy of this licence, visit http://creativecommons.org/licenses/by/4.0/. The Creative Commons Public Domain Dedication waiver (http://creativecommons.org/publicdomain/zero/1.0/) applies to the data made available in this article, unless otherwise stated in a credit line to the data. 
Table 1 Baseline characteristics, clinical care and outcomes, and indirect calorimetry measured resting energy expenditure in COVID19 ICU patients

\begin{tabular}{|c|c|c|c|c|}
\hline \multicolumn{5}{|l|}{ (a) Baseline characteristics $(n=22)$} \\
\hline Age (mean, range) & \multicolumn{4}{|l|}{$58(31-88)$} \\
\hline Male sex $(n, \%)$ & \multicolumn{4}{|l|}{$13(59)$} \\
\hline \multicolumn{5}{|l|}{ Race $(n, \%)$} \\
\hline African-American/Black & \multicolumn{4}{|l|}{$12(54)$} \\
\hline Caucasian/White & \multicolumn{4}{|l|}{$7(32)$} \\
\hline Hispanic & \multicolumn{4}{|l|}{$3(14)$} \\
\hline BMI (mean, range) & \multicolumn{4}{|l|}{$30.7(17.4-48.1)$} \\
\hline $\mathrm{BMI}>30(\%)$ & \multicolumn{4}{|l|}{55} \\
\hline Ventilator days (21-day study period only) (mean, sd) & \multicolumn{4}{|l|}{$14.4(4.7)$} \\
\hline Mortality (21-day study period only) $(n, \%)$ & \multicolumn{4}{|l|}{$3(14)$} \\
\hline Mortality (hospital mortality) (n, \%) & \multicolumn{4}{|l|}{$5(22)$} \\
\hline (b) Energy expenditure/data & D0-7 & D7-14 & D14-21 & $p$ value \\
\hline Measured REE in absolute kCal/day (all patients) (median, IQR) & $1568(1175-2215)$ & $1830(1465-2467)$ & $2789(1776-3262)$ & $<0.05$ \\
\hline Measured REE kCal/kg actual BW (non-obese, BMI < 30) (median, IQR) & $19.2(16.9-20.7)$ & $26(24.5-35.5)$ & $29(23-34.5)$ & $<0.05$ \\
\hline Measured REE kCal/kg actual BW (obese, BMI > 30) (median, IQR) & $17.5(12-19.25)$ & $21(20-23.5)$ & $31.5(24.8-36)$ & $<0.05$ \\
\hline Measured REE kCal/kg adjusted BW (obese, BMI > 30) (median, IQR) & $20(17-22.5)$ & $26.3(24-29)$ & $32.5(28.8-35.8)$ & $<0.05$ \\
\hline Measured REE kCal/kg actual BW (all patients) (median, IQR) & $19(13.7-28.5)$ & $26(22-42)$ & $30.4(27-35.8)$ & $<0.05$ \\
\hline (c) Clinical data & D0-7 & D7-14 & D14-21 & $p$ value \\
\hline Use of prone positioning (\%) (mean, sd) & $12.3(8.6)$ & $7(2.4)$ & $12.2(4.3)$ & 0.17 \\
\hline Use of paralysis with neuromuscular blocker (\%) (mean, sd) & $14.8(8)$ & $9.7(1.7)$ & $12.3(3.4)$ & 0.2 \\
\hline SOFA score (mean, sd) & $9(3.6)$ & $9(3.2)$ & $9.5(3.6)$ & 0.5 \\
\hline
\end{tabular}

a, patient characteristics; b, nutritional data for the first 3 weeks post-intubation; $c$, clinical care and outcomes data

$B W$ body weight; $B M I$ body mass index; $R E E$ resting energy expenditure, predicted REE via Harris-Benedict equation; $A d j B W$ adjusted bodyweight, $A B W$ actual body weight, obesity $\mathrm{BMI}>30$, non-obese $\mathrm{BMI}<30 \mathrm{l}, \mathrm{IQR}$ interquartile range, SOFA Sequential Organ Failure Assessment, sd standard deviation

Notes: All obese subjects had BMI measures between 30 and 50. $p$ values are for Kruskal-Wallis test

Subjects were withdrawn from this analysis upon extubation or death

mREE may not be significantly related to severity of organ failure and only minorly affected by paralysis/ prone positioning, as these were not significantly different over the study period (Table 1).

Longitudinal IC data presented here demonstrate a progressive hypermetabolic phenotype beginning 1 week post-intubation in COVID-19 ICU patients, with significantly greater $\mathrm{mREE}$ versus predictive equations or ASPEN-recommended $11-14 \mathrm{kcal} / \mathrm{kg} \mathrm{ABW}$ for obese subjects used currently to determine energy requirements. Our data support use of standard predictive equations or $\sim 20 \mathrm{kcal} / \mathrm{kg}$ as a reasonable approximation of mREE in 1st ICU week in COVID19 patients. Current ESPEN/ASPEN ICU guidelines suggest hypocaloric ( 70\% pREE) feeding during acute phase to prevent overfeeding risk as it is believed ICU patients have initial early endogenous nutrient production that we currently are unable to measure $[3,4]$.
To our knowledge, this is the first description of longitudinal mREE in a COVID-19 ICU population. The COVID-19 metabolic phenotype may be unique from previously described ICU models of metabolic response [2], with a more prolonged hypermetabolic phase that may be independent of severity of organ failure and, as previously published, may only be minorly affected by interventions such as paralysis [6]. Further, it is one of the largest single-ICU diagnosis cohorts with longitudinal IC measures for 21 days. In conclusion, we demonstrate progressive hypermetabolism and considerable variation in REE throughout ICU stay. We hope this data assists ICU clinicians in further understanding the effects of COVID-19 on metabolism and in assessing nutrition care needs. These data suggest personalization of nutrition delivery, including IC use $[3,5]$, should be considered to provide more accurate assessments of energy expenditure and help guide nutrition delivery in COVID-19 ICU patients. 


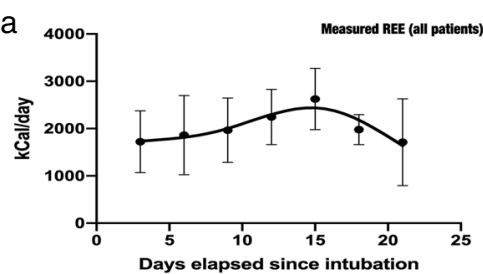

b
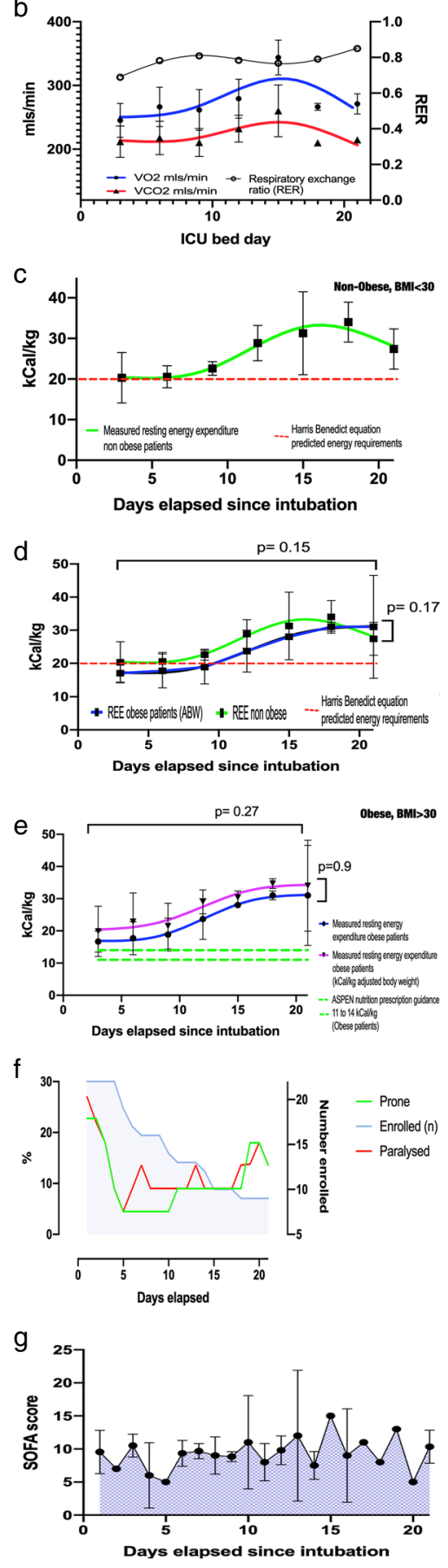

Fig. 1 Longitudinal energy expenditure, $\mathrm{VO} 2 \mathrm{NCO} 2$, and clinical care and SOFA score in intubated COVID-19 ICU patients over first 3 ICU weeks post-intubation. a Resting absolute energy expenditure over time in intubated patients with SARS-CoV-2 infection. b Resting $\mathrm{VO}_{2}$, $\mathrm{VCO}_{2}$, and RER over time in intubated patients with SARS-CoV-2 infection. c Resting energy expenditure over time in intubated nonobese patients with SARS-CoV-2 infection. $\mathbf{d}$ Resting energy expenditure over time in intubated non-obese and obese patients with SARS-CoV-2 infection. e Resting energy expenditure over time in intubated obese patients with SARS-CoV-2 infection. $\mathbf{f}$ Percentage (\%) of intubated patients with SARS-CoV-2 who were in prone position or paralyzed with neuromuscular blockers throughout study. Total number of subjects at any time point still participating in the study is presented in blue. $\mathbf{g}$ SOFA scores over time in intubated patients with SARS-CoV-2. Notes: (i) Longitudinal data presented as fitted regression curves (locally weighted scatter plot smoothing, with a 10-point smoothing window) with $72 \mathrm{~h}$ measured REE values presented as mean (sd), $p$ values are for MANOVA comparing both differences over time (longitudinal) and at individual time points. (ii) Metabolic cart measurements were able to be conducted on patients with an $\mathrm{FiO} 2<70 \%$ per manufacturer specifications and as described in new generation metabolic cart (QNRG) validation study reference [5]. (iii) Abbreviations: VO2, volume of oxygen consumed per minute; $\mathrm{VCO}$, volume of carbon dioxide consumed per minute; obesity, BMI > 30-50, non-obese, BMI $<30$; REE, resting energy expenditure; $\mathrm{kCal}$, kilocalories; RER, respiratory exchange ratio; ASPEN, American Society for Parenteral and Enteral Nutrition

\section{Acknowledgements}

The primary authors acknowledge the commitment and many hundreds of hours spent conducting this trial by the study research coordinators, respiratory therapists, dietitians, critical care attendings, nurses, and other ICU staff at Duke University Hospital that made the many daily measurements in critically ill COIVD-19 patients possible.

We also acknowledge the LEEP-COVID study group co-authors who made this research possible: Anthony Sung MD, Marat Fudim MD, Lindsie Boerger RD, Kathryn Lessig RD, Jessica Lumbard BS, Leslie C. Murray RD, Sue Steves RD, Jhana Parikh BS, Jacob Ribet BS, RRT LDN, and Melanie Hollidge MD.

\section{Authors' contributions}

Concept and design: Whittle, Molinger, and Wischmeyer

Acquisition, analysis, or interpretation of data: Whittle, Molinger, MacLeod, Parikh, Ribet, Wischmeyer, Sung, Boerger, Murray, Steves, Lessig, Lumbard, Fudim, and Hollidge

Drafting of the manuscript: Whittle, Haines, and Wischmeyer

Critical revision of the manuscript for important intellectual content: Whittle, MacLeod, Haines, Wischmeyer, and Sung

Statistical analysis: Whittle

Administrative, technical, or material support: Molinger, Parikh, Ribet, Boerger, Murray, Steves, Lumbard, Fudim, and Hollidge

Supervision: Whittle and Wischmeyer

The authors read and approved the final manuscript.

\section{Funding}

This study was funded in part by an investigator-initiated grant from Baxter Inc. (Deerfield, IL) to Paul E. Wischmeyer via Duke University. The sponsor (Baxter) did not participate in the design and conduct of the study; collection, management, analysis, and interpretation of the data; preparation, review, or approval of the manuscript; and decision to submit the manuscript for publication. Only the authors and investigators at Duke University participated in design and conduct of the study; collection, management, analysis, and interpretation of the data; preparation, review, or approval of the manuscript; and decision to submit the manuscript for publication. 


\section{Ethics approval and consent to participate}

LEEP-COVID study was approved by Duke Institutional Review Board. A waiver of consent was granted by Duke IRB due to minimal risk to patient from FDA-approved QNRG indirect calorimeter assessment. All patients were provided an information sheet when able to be awake and oriented (if possible) and given option to withdraw from the study with no data retained.

\section{Consent for publication}

Not applicable; all authors have seen and approved the final version of the manuscript.

\section{Competing interests}

Dr. Wischmeyer reports receiving investigator-initiated grant funding related to this work from National Institutes of Health, Canadian Institutes of Health Research, Baxter, and Fresenius. Dr. Wischmeyer has served as a consultant to Abbott, Fresenius, Baxter, Cardinal Health, and Nutricia, for research related to this work. Dr. Wischmeyer has received unrestricted gift donation for nutrition research from Musclesound. Dr. Wischmeyer has received honoraria or travel expenses for CME lectures on improving nutrition care from Abbott, Baxter, and Danone-Nutricia.

Received: 3 July 2020 Accepted: 14 September 2020

Published online: 28 September 2020

\section{References}

1. Berlin DA, Gulick RM, Martinez FJ. Severe Covid-19 [published online ahead of print, 2020 May 15]. N Engl J Med. 2020; https://doi.org/10.1056/ NEJMcp2009575.

2. Uehara M, Plank LD, Hill GL. Components of energy expenditure in patients with severe sepsis and major trauma: a basis for clinical care. Crit Care Med. 1999;27(7):1295-302.

3. Singer $P$, Blaser AR, Berger MM, Alhazzani W, Calder PC, Casaer MP, Hiesmayr M, Mayer K, Montejo JC, Pichard C, et al. ESPEN guideline on clinical nutrition in the intensive care unit. Clin Nutr. 2019;38(1):48-79.

4. McClave SA, Taylor BE, Martindale RG, Warren MM, Johnson DR, Braunschweig C, McCarthy MS, Davanos E, Rice TW, Cresci GA, et al. Guidelines for the provision and assessment of nutrition support therapy in the adult critically ill patient: Society of Critical Care Medicine (SCCM) and American Society for Parenteral and Enteral Nutrition (A.S.P.E.N.). JPEN J Parenter Enteral Nutr. 2016;40(2):159-211.

5. Oshima T, Delsoglio M, Dupertuis YM, Singer P, De Waele E, Veraar C, Heidegger CP, Wernermann J, Wischmeyer PE, Berger MM et al: The clinical evaluation of the new indirect calorimeter developed by the ICALIC project. Clin Nutr. 2020:S0261-5614(20)30040-6. Doi: https://doi.org/10.1016/j.clnu. 2020.01.017. Online ahead of print.

6. Koekkoek WAC, Menger YA, van Zanten FJL, van Dijk D, van Zanten ARH. The effect of cisatracurium infusion on the energy expenditure of critically ill patients: an observational cohort study. Crit Care. 2020;24(1):32.

\section{Publisher's Note}

Springer Nature remains neutral with regard to jurisdictional claims in published maps and institutional affiliations.

Ready to submit your research? Choose BMC and benefit from:
- fast, convenient online submission
- thorough peer review by experienced researchers in your field
- rapid publication on acceptance
- support for research data, including large and complex data types
- gold Open Access which fosters wider collaboration and increased citations
- maximum visibility for your research: over 100M website views per year
At BMC, research is always in progress.
Learn more biomedcentral.com/submissions

